\title{
The Development and Integration of Humanitarian Engineering Curriculum in an Engineering Technology Program
}

\section{Mr. Aaron Brown, Metropolitan State University of Denver}

Aaron Brown is Assistant Professor of Mechanical Engineering Technology and Coordinator at Metropolitan State University of Denver. His education includes: B.S., California State University-Chico; M.S., University of Colorado-Boulder; PhD Candidate Civil Systems Engineering; University of Colorado at Boulder

Professor Brown's background includes aerospace industry work. Among his notable project contributions were design work on the landing mechanism for the Mars Science Laboratory Rover Mission AKA Curiosity. Mechanism design work for Hubble Robotics and on Global Precipitation Measurement Instrument Missions. Additionally, Professor Brown has worked at the National Institute of Standards and Technology designing test equipment to measure stress-strain relationships to superconductor performance.

His past work on the tethering landing mechanism used to lower the Mars rover Curiosity to the Red Planet's surface is part of a \$2.5 billion program NASA says will assess whether the Gale Crater area of Mars has ever had the potential to support a habitable environment.

Professor Brown runs the NASA Space Grant program at MSU Denver. His current research interests include electric vehicle optimization and design, robotics, and harvesting solar energy, green energy, and Humanitarian Engineering. He created a course called Humanitarian Engineering, where he took students to Costa Rica for 10 days in January 2013 to work on a water project for a new school.

Concurrently with his work at MSU Denver, Professor Brown is pursuing a PhD degree in Civil System Engineering under the advising of Dr. Bernard Amadei with a topic in Sustainable Community Development, and implementing technologies that help marginalized communities.

With limited free time his interests outside of work include cycling (he is an ex-professional bike racer), skiing, hiking, travel and exploring other cultures.

Mr. Duane B Swigert, Metropolitan State University of Denver 


\title{
The Development and Integration of Humanitarian Engineering Curriculum in an Engineering Technology Program
}

\author{
Brown, Aaron1; Swigert, Duane \\ Metropolitan State University of Denve, Department of Mechanical Engineering Techmology Po box 173362, Denver, Co
}

\begin{abstract}
Humanitarian Engineering is the application of engineering research and work to directly benefit marginalized people (1). Marginalization in this case can be defined as applying to people who lack the capital to acquire a basic place in society due to a host of reasons. Some common examples of the forces that drive people into a marginalized position include poverty, lack of local language competency, low education attainment opportunity, health issues, and environmental structure related to region, government policies, class systems, etc.(2) Humanitarian engineering is designing to apply engineering knowledge to directly benefit and improve the position and capacity of these marginalized people. In general, humanitarian engineering focuses on appropriate technologies using locally sourced, available resources that are affordable and sustainable. It is participatory in nature and often involves simple solutions to solve problems related to basic needs (i.e. clean water, air, sanitation, heat, shelter etc.). As such, training for one who participates in humanitarian engineering incorporates history, politics, economics, sociology, language, as well as rigorous engineering basics.

The nature of humanitarian engineering projects offer a unique opportunity to teach students through an approach that integrates theory with a practical hands-on experience. By creating a learning environment through helping marginalized communities, students are challenged with problems that enhance their critical thinking ability and help them acquire new technical skills. Moreover, the service learning aspect of these projects contribute to students walking away from the experience with a bigger picture and awareness of the world and how they can contribute to solving some of humanity's challenges.

This paper focuses on the development and introduction of humanitarian engineering curriculum to an existing engineering technology program. Specifically, the paper will highlight three innovations which were integrated into the engineering technology program at Metropolitan State University of Denver:

$\square$ The development of a course titled Humanitarian Engineering" whose first edition took students abroad to do a community development project in Costa Rica.

$\square$ The integraing of a projects class with focus on an engineering project which had students design, construct, test and implement soda-can solar furnaces for a local marginalized community in Denver

$\square$ Thecreation of a humanitarian engineering student club and how that club is increasing student involvement in undergraduate research projects and its role in service learning.
\end{abstract}

* Corresponding author. Tel.: 303-556-3083; fax: 303-556-2972

E-mail address: abrow118@msudenver.edu 


\section{Background}

Metropolitan State University of Denver offers bachelor's and master's degrees in a large variety of programs on the Auraria Campus in the heart of downtown Denver. The MSU Denver student body is approximately 23,000 students and educates more undergraduate Coloradans than any other institution in Colorado. Among the programs and degrees offered at MSU Denver are three disciplines in Engineering Technology: Civil, Mechanical and Electrical. The programs are ABET accredited and, under the guidelines of this accreditation, the Engineering Technology degree plans requires upper division elective courses to be completed by students. The humanitarian engineering curriculum, described in this paper, is designed to act as upper division elective credits, giving students a unique opportunity to do an applied service-learning project as part of their educational experience. Moreover, these classes are designed to broaden the students' engineering skills, competency and confidence. The nature of the projects also contribute to providing a broader picture of the world and students' role in that context. This coincides with Metro State's Mission: “The mission of Metro State is to provide a high-quality, accessible, enriching education that prepares students for successful careers, post-graduate education, and lifelong learning in a multicultural, global, and technological society.” (3)Furthermore, the American Society of Mechanical Engineering list as the number one fundamental principle of the profession to: "Utilize the professional skills for the welfare of human and society.”-(4) something this curriculum aims to encourage as it helps students develop global engineering skills (5)

\section{Marginalization Metrics}

Humanitarian Engineering is aimed at providing services to people who are marginalize and so, defining the metrics of marginalization is significant. Commonly marginalization is associated with poverty. Some of the common problems that pervade among people living in the oppressive conditions of poverty include, but are not limited to items such as lack of adequate nutrition, access to health care and medicines, adequate shelter, heating etc. People living in communities with these barriers can be classified as marginalized. According to Onyije \& Francis in their paper "Technology Solution for the Marginalized" (2) "Marginalization can be defined as not belonging to the main stream culture, and thus lacking the "social capital" to partake from the benefits of a society and to have an effect on its culture. Reasons might be found in poverty, lack of competences in mainstream language and/or culture, or lack of motivation.”

\section{Creating Humanitarian Engineering Curriculum}

To provide relevant educational experiences for students, two omnibus* courses were developed which incorporate the philosophy of humanitarian engineering in providing services to people who are marginalized.

\section{Humanitarian Engineering Study Abroad Course}

The first foray into humanitarian engineering curriculum at MSU Denver was offered through a study abroad course created titled "Humanitarian Engineering". This course took twelve students on a fourteen day trip to Costa Rica where the students executed a sustainable 
engineering project in the local community to meet that population's basic engineering needs.

This class included lectures that conveyed the principles of humanitarian engineering including world need and the affect students might have in marginalized communities using the skills they are building through their education. Additionally, the concepts of the lectures were applied in both the assessment of the local community and the implementation of a project to serve the determined needs. The project that was selected was chosen based on an appraisal of that community which loosely followed the CARE (6) guidelines for community appraisal and included analysis of culture, capacity, and appropriateness.

From the appraisal, it was determined that the most appropriate project (7) for the students to engage in was a solar water heater for the local school. The students designed and built a very simple but effective water heater using local materials and costing less that $\$ 100$ to build. The design was very specific to the region as the proximity of Costa Rica to the equator allowed a shallow angle for the panel that water flowed over which contributed to a measured $70^{\circ} \mathrm{F}$ temperature gain which made the design applicable and effective for the design challenge.

Upon completion of the trip, students were required to write a reflective project report and present the experience to an audience through the avenue of the undergraduate research symposium at MSU Denver. Additionally, all participating students were surveyed for their perspective on the course experience. The pervading feedback suggested that the most impactful component of the experience was the service aspect of the project and, overwhelmingly the students expressed experiencing a changed perspective of the world and their role in it.

\section{Projects Course}

Through the experience and surveys of the study abroad course, it was recognized that students exhibited a strong connection to the service learning aspect of humanitarian engineering. While there is a pervading image of these types of projects being conducted in far off places, there are also people who live in conditions of marginalization and poverty within the United States as well (8) who also could benefit from humanitarian engineering interventions. Furthermore, the logistics and cost of travel abroad courses can be limiting for many students. It was though that perhaps an equally beneficial educational experience could be created through local community projects. To offer credit opportunity for local projects, a summer course was created titled "Project Experience" which provided, as one of the offered options, a local humanitarian engineering project. The selected project involved students in the design, construction and implementation of aluminium can solar furnaces for the community of Westwood Denver which qualifies on many levels under the metrics of marginalization $(9,10)$.

Through a community appraisal, it was determined that one of the largest burdens for the people of Westwood was the poor housing stock and its effect on heating expenses. To address this issue, several solutions were considered and the aluminium can solar furnace was selected as the chosen technology intervention for its combination of low price, potential savings and appropriateness, both as a student project and for the community.

The aluminium can solar furnace is a cheap and effective method for using the sun to provide warm air using greenhouse principles. In this simple design, sunlight passively heats air within columns of aluminium cans, and the air then flows into the living space. The design is very flexible and can be tailored to use locally available materials, and scaled to perform at the needed level. 


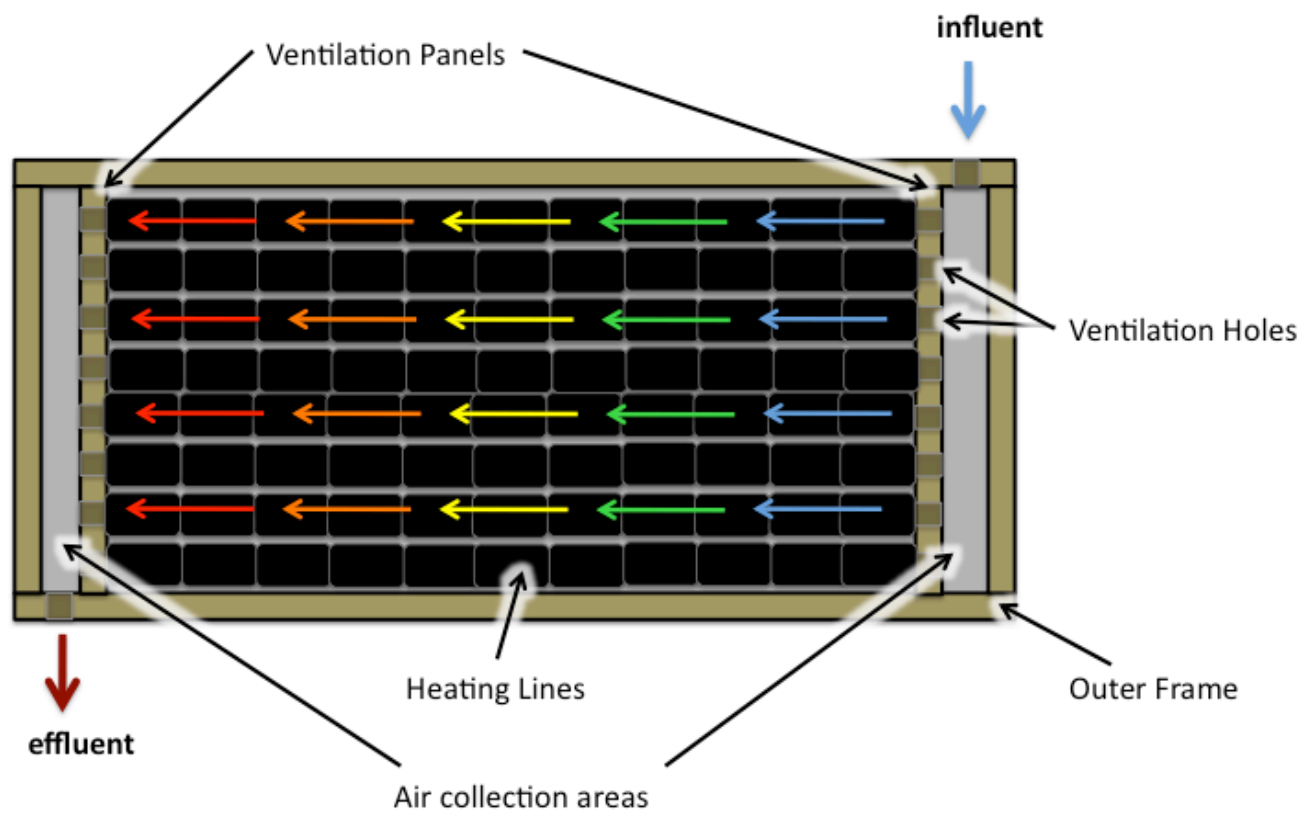

Figure 1. Solar collector concept design

For this class, students designed built and tested different variations of the furnaces. From the data collected it was determined that the community households could save \$20-\$30 a month with the design solution created, which cost approximately $\$ 35$ to construct.

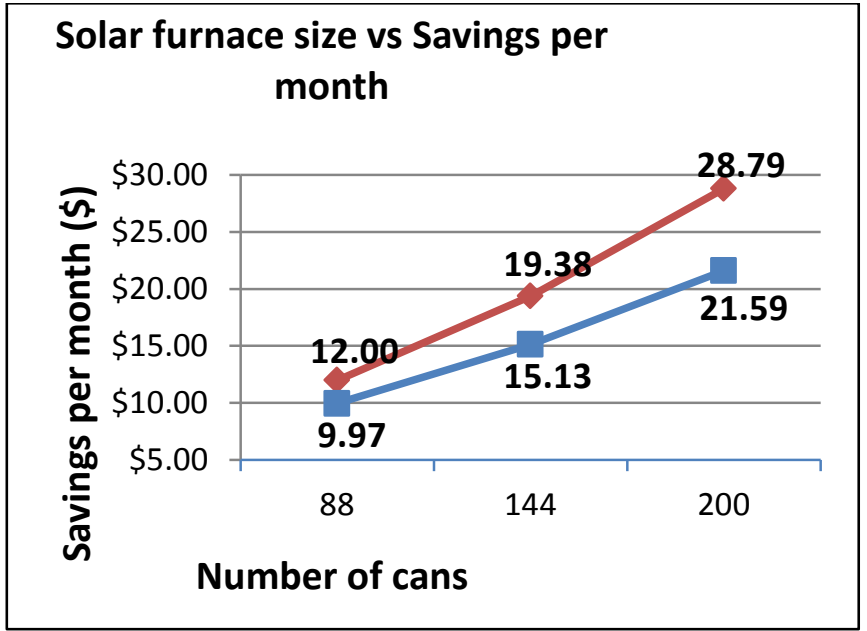

Fig 2. Saving Estimates per unit size

The students settled on a 144 can design and provided 4 of the units to the community (who recently reported an average \$25 per month savings vs. last year’s bill).

Surveys were taken of the involved students which again indicated that the service learning aspect of the project had greatly affected their perspective of their role in the world 


\section{Humanitarian Engineering Club}

To encourage more student participation and interest in humanitarian engineering activities, a student club named “Humanitarian Engineering Club” was created. After six months of existence, there are approximately 35 members in this club and, of those, five have signed up for the next study abroad "Humanitarian Engineering" course to Costa Rica to take place in May 2014 which indicates that the Humanitarian Engineering Club is a good direction for recruitment and awareness for the students. Students involved in the club are also working on faculty directed projects mostly in developing simple technologies that can potentially be used for future community work (i.e. bio-gas generators, solar de-salinization units etc).

\section{Discussion}

Through the integration of two courses and a student club focused on humanitarian engineering education, the Engineering Technology Department at MSU Denver is providing a shifted paradigm for engineering education which emphasizes skill building through service learning activities. Surveys have indicated that the students involved in this curriculum have a shifted perspective their role in the world and how they can contribute to solving some of humanity's challenges. Overwhelmingly the students have expressed in surveys as well as through reflective reports that the service learning aspect benefited their educational experience. MSU Denver intends to expand on this momentum. Presently there are humanitarian engineering study abroad classes being planned for the Dominican Republic and the Galapagos Islands as well as some local activities. Additionally, undergraduate research is being conducted now to develop smallscale systems which can be useful for developing community needs. The Humanitarian Engineering Club is acting as a recruitment tool for these projects and future class offerings.

\section{Bibliography}

(1) Mitcham, Munoz, Humanitarian Engineering, Synthesis Lectures on Engineers, Technology and Society 2010, 87 pages, (doi:10.2200/S00248ED1V01Y201006ETS012) (2) Onyije \& Francis ,“Technology Solution for the Marginalized” European Scientific Journal June edition vol. 8, No.13, 2012

(3) website: https://www.msudenver.edu/strategicplanning/missionvaluesvision

(4) website: https://www.asme.org/

(5) D. Weichert, B. Rauhut, R. Schmidt, Educating the Engineer for the 21st Century, ISBN: 978-1-4020-0096-6 (Print) 978-0-306-48394-3 (Online)

(6) R. Caldwell, "Project Design Handbook," Tango International, Cooperative for Assistance and Relief Everywhere, Inc. (CARE), 2002

(7) M. Bauer, Quantitative Assessment of Appropriate Technology, 2013 Masters Thesis. Mortenson Center for Engineering in Developing Communities, CU Boulder

(8) Bitler, M., \& Haider, S. J. “An Economic View of Food Deserts in the United States. Understanding the Economic Concepts and Characteristics of Food Access” Department of Agriculture-Economic Research Service (USDA-ERS) 2009

(9) City-Data. Westwood neighborhood in Denver, Colorado (CO), 80219 detailed profile. Visited October 2012. <http://www.city-data.com/neighborhood/Westwood-Denver-CO.html>. (10) Re:Vision International. Our Impact. Visited October 2012. $<$ http://www.Re:Visioninternational.org/index.php/en/our-impact?id=112>. 


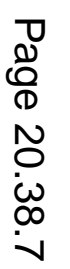

